\title{
Kinetics of Thermal Decomposition of Iron Carbonate
}

\author{
A.A. El-Bellihi \\ Chemistry Department, Faculty of Science, Benha University, \\ Benha, Egypt
}

$\mathbf{T}$

HE THERMAL decomposition of iron cabonate in air was

studied by means of DTA-TG, XRD, SEM and Mossbauer measurements. The kinetics of the thermal decomposition process were studied using isothermal and non-isothermal thermogravimetric techniques. The results show that the thermal decomposition proceeds in one step to iron oxide. Kinetic analysis of isothermal data of the decomposition reaction in the light of various solid state reaction models revealed that the reaction is best described by the diffusion models. Kinetic analysis of the dynamic TG curves were discussed with reference to Diefallah's composite integral method, in comparison with the integral methods due to Coats-Redfern and to Ozawa. The activation parameters were calculated and the results of the isothermal and dynamic integral methods which were compared to each other were discussed.

Progress in an increasing number of areas of technology and hence industry is being recognized as directly related to understanding the factors influencing reactivity of solids and how they react ${ }^{(1)}$. Thermoanalytical methods have been used extensively for studying the kinetics of thermal decomposition of solids. The kinetic studies have proceeded in two directions: using powdered materials and using single crystals. The former studies are much more extensive than the latter. The essential features of solids- state decompositions are: the destruction of the crystal lattice of the reactant, the breaking and the redistribution of chemical bonds followed by the formation of the crystal lattice of the reaction product and lastly, the diffusion of one component or the other through the product layer of the propagation of the dissociation reaction. The kinetics of thermal decomposition of solids are affected by experimental factors ${ }^{(2)}$, such as heating rate, particle size, sample mass and holder design.

Iron carbonate $\left(\mathrm{FeCO}_{3}\right)$ exists commonly in the rock (siderite core). It plays a major role in biogeochemical cycles as electron donor and acceptor in oxidationreduction reactions.

Email: aaelbellihi@yahoo.com 
In the present study, the thermal decomposition of iron carbonate in air was studied using DTA- TGA, XRD, and Mossbauer spectra. The kinetics of the thermal decomposition process were carried out using isothermal and dynamic thermogravimetric means and considered in light of various models and computational methods of solid state reactions ${ }^{(3-12)}$. The kinetic analysis of dynamic TG data were discussed in view of three integral methods suggested by Ozawa $^{(13)}$, Coats-Redfern ${ }^{(14)}$, and Diefallah's composite method ${ }^{(5)}$ and the results were compared with those obtained under isothermal conditions .

\section{Experimental}

Ferrous carbonate was prepared according to the method described by Xuan et al. ${ }^{(15)}$. A $(0.002 \mathrm{~mol})$ solution of $\mathrm{FeCl}_{3} \cdot 6 \mathrm{H}_{2} \mathrm{O}$ was dissolved in $35 \mathrm{ml}$ deionized water under continuous stirring to form a red solution, then add $(0.636$ gm) $\mathrm{Na}_{2} \mathrm{CO}_{3}$ slowly, and after $10 \mathrm{~min}$ add $0.40 \mathrm{gm}$ of ascorbic acid to the above solution. After being stirred for further 5 min the solution was sealed in autoclave and kept at $160^{\circ} \mathrm{C}$ for $3 \mathrm{hr}$ then cooled in air. The final product was separated and washed with water and alcohol and dried at $50^{\circ} \mathrm{C}$.

The thermal decomposition of iron carbonate in air was investigated using Shimadzu model DT 40 Thermal Analyzer. The kinetics of the thermal decomposition of iron carbonate were studied using isothermal and dynamic TG techniques. In the isothermal studies the reaction temperature was varied between $480-520^{\circ} \mathrm{C}$, whereas the dynamic experiments were carried out at heating rates of $5,10,15,20$ and $30 \mathrm{~K} \mathrm{~min}^{-1}$. The sample weights were about 6$8 \mathrm{mg}$ to ensure linear heating rates and accurate temperature measurements.

Mossbauer spectra of the samples calcined at different temperatures were determined at room temperature relative to iron foil using Mossbauer spectrometer with ${ }^{57} \mathrm{Co}$ source in metallic iron.

X-ray diffraction patterns for the calcined samples were recorded with a Philips PW 1710 X-ray diffractometer using a Nickel - filtered, $\mathrm{Cu}$ radiation $(\lambda=1.5405 \stackrel{\circ}{A})$.

SEM photographs of samples were taken using a Jeol JSM-35C scanning electron microscope.

\section{Results and Discussion}

Figure 1 shows the DTA-TG curves obtained for the thermal decomposition of iron carbonate in air. Figure 1 shows the thermal decomposition of iron carbonate at temperature below $600^{\circ} \mathrm{C}$ occurs. It is shown from one DTA curve in Fig. 1 one exothermic peak at $495^{\circ} \mathrm{C}$ accompanied with a weight loss of about $32 \%$ (theoretical value $31.1 \%$ ). This step is due to the decomposition of iron carbonate to $\mathrm{Fe}_{2} \mathrm{O}_{3}$.

Egypt. J. Chem. 53, No. 6 (2010) 


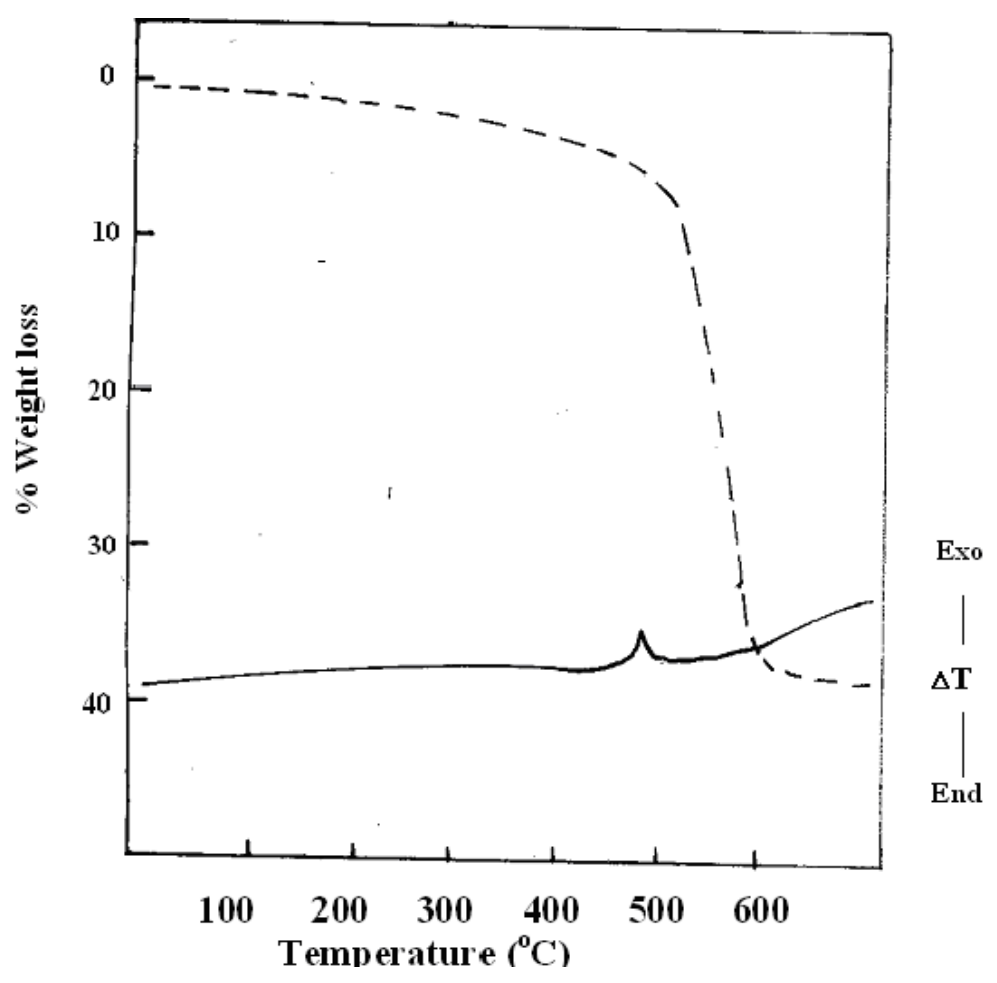

Fig. 1. DTA-TG of iron carbonate in air and heating rate $20^{\circ} \mathrm{deg} / \mathrm{min}$.

Mossbauer spectra at room temperature of samples calcined at different temperatures are shown in Fig. 2. The spectra at room temperature (curve 2a) shows an isomer shift of $1.25 \mathrm{mms}^{-1}$ and quadrapole splitting of $1.6 \mathrm{mms}^{-1}$. Whereas the spectra of the sample calcined at $550^{\circ} \mathrm{C}$ (curve $2 \mathrm{~b}$ ) shows the appearance of sextet. It consists of two $\mathrm{Fe}$ (III) oxides, one with superparamagnetic doublet and a six-fold spectrum due to the large particle size $^{(16)}$. For the sample calcined at higher temperature, $800^{\circ} \mathrm{C}$, the Mossbauer spectra shows a hyperfine splitting of $510 \mathrm{kOe}$ and the supermagnetic disappears (curve2c), thus giving rise to the characteristic spectrum of $\mathrm{Fe}_{2} \mathrm{O}_{3}{ }^{(7,17)}$. This is in agreement with the results obtained in the DTA-TG. 


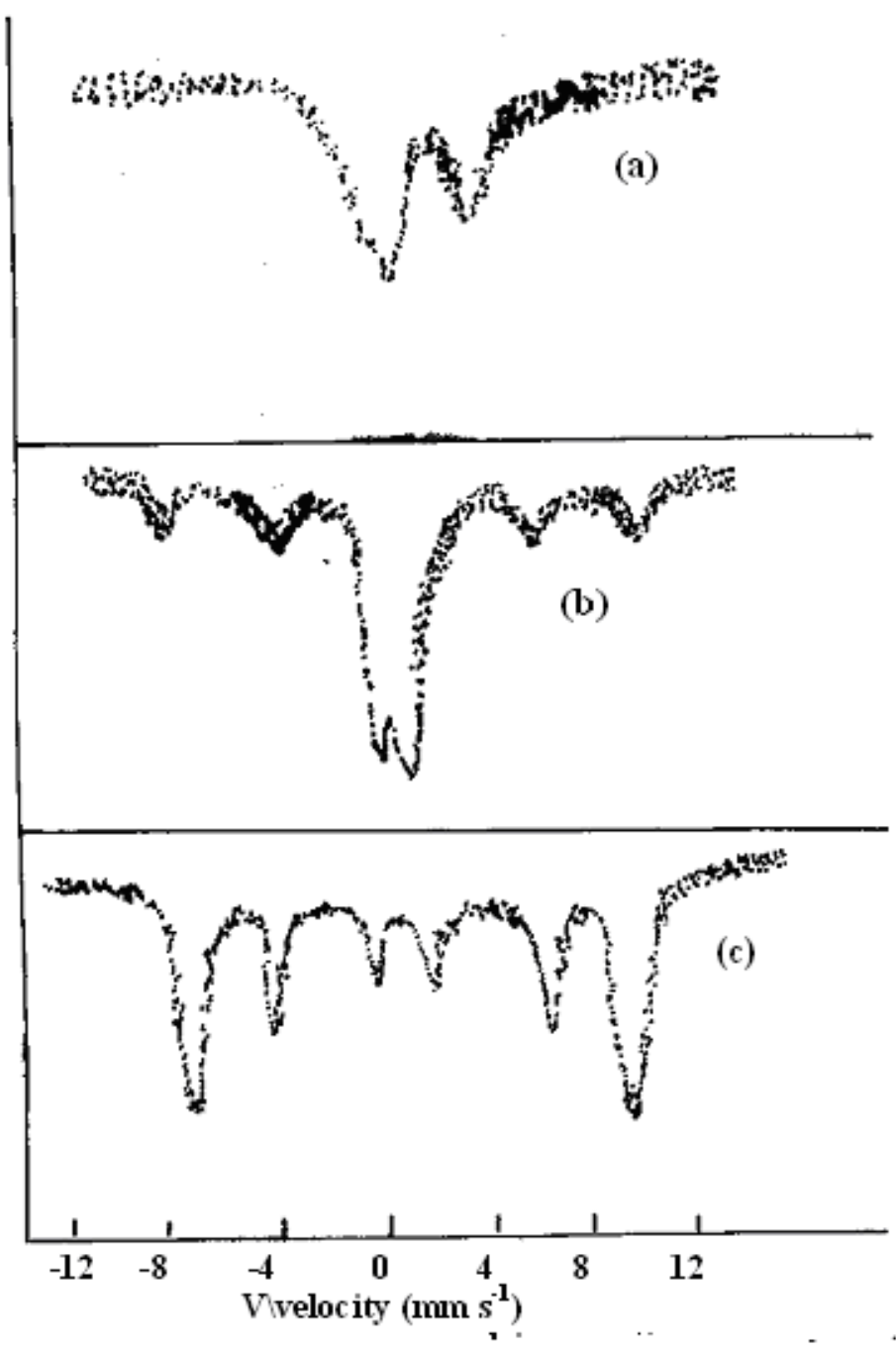

Fig. 2. Mossbauer spectra of iron carbonate calcined at different temperatures; a) room temperature, b) sample calcined at $550^{\circ} \mathrm{C}$ and c) sample calcined at $800^{\circ} \mathrm{C}$.

$\mathrm{X}$-ray diffraction patterns of the decomposition products of iron carbonate were determined for the solid calcined at 550 and $800{ }^{\circ} \mathrm{C}$ and depicted in Fig.3. Figure 3 (a) shows X-ray diffractogram for the sample dried at room temperature corresponding to iron carbonate. The diffractogram of the sample calcined at $550^{\circ} \mathrm{C}$ consists of very poorly crystallized $\alpha-\mathrm{Fe}_{2} \mathrm{O}_{3}$ phase (Fig. $3 \mathrm{~b}$ ). This is in agreement with the Mossbauer spectra. Heating of ferrous carbonate at $800^{\circ} \mathrm{C}$ led to the formation of well crystalline $\alpha-\mathrm{Fe}_{2} \mathrm{O}_{3}$ (Fig. $3 \mathrm{c}$ ).

Egypt. J. Chem. 53, No. 6 (2010) 


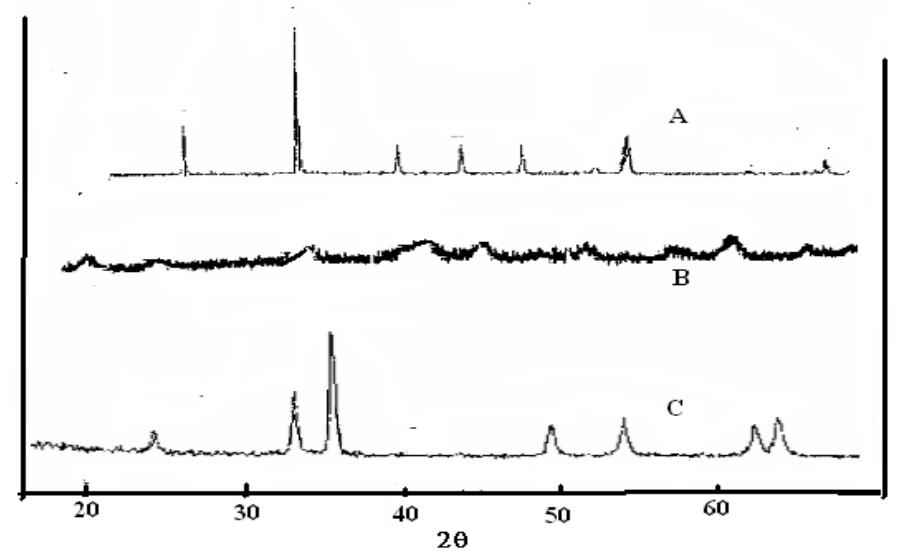

Fig. 3. X-ray diffraction pattern of iron carbonate. (a) at room temperture, (b) sample calcined at $550^{\circ} \mathrm{C}$ and(c) sample calcined at $800^{\circ} \mathrm{C}$.

SEM micrographs of iron carbonate samples are shown in Fig. 4. The results show that there is a remarkable changes in texture and morphology that accompany the thermal decomposition of siderite. The original sample consists of large crystals (Fig. 4a) with defined faces and edges. Whereas the SEM micrographs for the sample calcined at $550^{\circ} \mathrm{C}$ showed that iron carbonate crystals lost their morphology into small crystals (Fig. 4b). The surface micrograph of the siderite sample calcined at $800^{\circ} \mathrm{C}$ showed that there is aggregations of the small crystallites into large aggregates of $\mathrm{Fe}_{2} \mathrm{O}_{3}$ (Fig. 4c).

The kinetic model functions $\mathrm{g}(\alpha)$ listed in Table 1 were examined for the thermal decomposition of iron carbonate by conventional isothermal analysis. Under isothermal conditions, the rate constant, $\mathrm{k}$, is independent of reaction time and so $g(\alpha)=\mathrm{kt}$. A plot of $\mathrm{g}(\alpha)$ versus time should thus give a straight line if the correct form of $\mathrm{g}(\alpha)$ is used. The isothermal $\alpha-\mathrm{t}$ data were analysed according to the various kinetic models ${ }^{(3-12)}$ by regression analysis. Figure 5 shows typical a-t curves for the isothermal decomposition of siderite. The best fit of the decomposition data was obtained by Jander's equation for diffusion controlled process into a sphere $\left(\mathrm{D}_{3}\right)$. 



Fig. 4. Scanning electron micrographs of iron carbonate. (a) at room temperture, (b) sample calcined at $550^{\circ} \mathrm{C}$ and(c) sample calcined at $800^{\circ} \mathrm{C}$. 
TABLE 1. Kinetic model equations used in this work.

\begin{tabular}{|l|c|c|}
\hline Reaction model & Symbol & $\mathbf{g}(\boldsymbol{\alpha})$ \\
\hline Two dimensional phase boundary & $\mathrm{R}_{2}$ & $1-(1-\alpha)^{1 / 2}$ \\
\hline Three dimensional phase boundary & $\mathrm{R}_{3}$ & $1-(1-\alpha)^{1 / 3}$ \\
\hline One dimensional diffusion & $\mathrm{D}_{1}$ & $\alpha{ }^{2}$ \\
\hline two dimensional diffusion & $\mathrm{D}_{2}$ & $\alpha+(1-\alpha) \ln (1-\alpha)$ \\
\hline three dimensional diffusion & $\mathrm{D}_{3}$ & {$\left[1-(1-\alpha)^{1 / 3}\right]^{2}$} \\
\hline three dimensional diffusion & $\mathrm{D}_{4}$ & $(1-2 / 3 \alpha)-(1-\alpha)^{2 / 3}$ \\
\hline Random nucleation Two-dimensions & $\mathrm{A}_{2}$ & {$[-\ln (1-\alpha)]^{1 / 2}$} \\
\hline Random nucleation Three-dimensions & $\mathrm{A}_{3}$ & {$[-\ln (1-\alpha)]^{1 / 3}$} \\
\hline Random nucleation Three-dimensions & $\mathrm{A}_{4}$ & {$[-\ln (1-\alpha)]^{1 / 4}$} \\
\hline First order kinetics & $\mathrm{F}_{1}$ & $-\ln (1-\alpha)$ \\
\hline Second order kinetics & $\mathrm{F}_{2}$ & $1 /(1-\alpha)$ \\
\hline Third order kinetics & $\mathrm{F}_{3}$ & {$[1 /(1-\alpha)]^{2}$} \\
\hline Prout - Thompkins & $\mathrm{B}_{1}$ & $\ln [\alpha /(1-\alpha)]^{2}$ \\
\hline Exponential law & $\mathrm{E}_{1}$ & $\ln \alpha$ \\
\hline
\end{tabular}



Time (min.)

Fig. 5. $\alpha / t$ curves for isothermal decomposition of iron carbonate. 
In order to obtain variable kinetic parameters from the rising temperature method, five different heating rates 5, 10, 15, 20 and $30 \mathrm{deg} \mathrm{min}^{-1}$, were employed using a small mass $(\sim 5 \mathrm{mg})$. Several methods can be used for calculation of kinetic parameters from non-isothermal TG- data.

In the present study, the analysis were carried out using approximate computational approaches due to Ozawa ${ }^{(13)}$ method, the Coots-Redfern ${ }^{(14)}$ method, Madhusudanan method ${ }^{(18)}$ and composite method ${ }^{(5)}$.For the integral composite method, the fractional decomposition values $(\alpha)$ obtained at different heating rates (b.) are superimpresed on one master curve.

In general, the rate constant, $\mathrm{k}$ of a solid-state reaction is given by the formal kinetic equation:

$$
\frac{\mathrm{d} \alpha}{\mathrm{dt}}=\mathrm{kf}(\mathrm{a})=\mathrm{Ae}^{-\mathrm{E} / \mathrm{RT}} \mathrm{f}(\mathrm{a})
$$

where $\mathrm{A}$, is the preexponential factor; $\mathrm{E}$, the activation energy; $\mathrm{R}$, the gas constant; $\mathrm{T}$, the absolute temperature and $\mathrm{f}(\mathrm{a})$, the kinetic function which takes different forms depending on the particular reaction rate equation ${ }^{(3-12)}$.

In the non-isothermal kinetics the time dependence on left side of equation(1), is eliminated using constant heating rate $b=d T / d t$, so that $T=T_{0}+\beta$, where $T_{o}$ is the starting temperature and $t$ is the time of heating. Using integral methods of analysis, equation (1) may be written as

$$
\mathrm{g}(\alpha)=\frac{\mathrm{A}}{\beta} \int_{\mathrm{T}_{0}}^{\mathrm{T}} \mathrm{e}^{-\mathrm{E} / \mathrm{RT}} \mathrm{dt}
$$

Because the reaction rate is negligible at low temperatures, hence:

$$
g(\alpha)=\frac{A}{\beta} \int_{0}^{T} e^{-E / R T} d t
$$

Integration of this equation leads to Doyle's equation ${ }^{(19)}$

$$
g(\alpha)=\frac{A E}{R \beta}\left[\left[\frac{e^{-x}}{x}-\int_{0}^{\infty} \frac{e^{-u}}{u} d u\right]=\frac{A E}{R \beta} P(x)\right.
$$

where $\mathrm{u}=(\mathrm{E} / \mathrm{RT})$ and $\mathrm{x}$ is the corresponding value of $\mathrm{u}$ at which a fraction of material has decomposed. This equation has been reformulated as ${ }^{(20)}$ :

$$
\ln \mathrm{g}(\alpha)-\ln \mathrm{P}(\mathrm{x})=\ln \quad \frac{\mathrm{AE}}{\mathrm{R} \beta}=\mathrm{B}
$$

where $\mathrm{B}$ is a constant for a particular reaction at a constant heating rate $\mathrm{b}$. The integral function $\mathrm{P}(\mathrm{x})$ is not definite and may be written in expanded form and estimated using procedure of trial-and-error type involving iteration ${ }^{(21)}$.

In the Coats-Redfern mothod ${ }^{(14)}$, the function $\mathrm{g}(\mathrm{a})$ is approximated to the form

Egypt. J. Chem. 53, No. 6 (2010) 


$$
\mathrm{g}(\alpha)=\frac{\mathrm{ART}^{2}}{\mathrm{E}}\left[\left[1-\frac{2 \mathrm{RT}}{\mathrm{E}}\right] \mathrm{e}^{-\mathrm{E} / \mathrm{RT}}\right.
$$

The equation has been written in the form:

$$
-\ln \left[\left[\frac{\mathrm{g}(\alpha)}{\mathrm{T}^{2}}\right]=-\ln \frac{\mathrm{AR}}{\mathrm{E}}\left(1-\frac{2 \mathrm{RT}}{\mathrm{E}}\right)+\frac{\mathrm{E}}{\mathrm{RT}}\right.
$$

The quantity $\ln \frac{A R}{\beta E}\left(1-\frac{2 R T}{E}\right)$ is reasonably constant for most values of $E$ and in the temperature range over which most reactions occur. However, both $\mathrm{E}$ and A could vary with the experimental heating rate.

In the Ozawa method ${ }^{(13)}$, a master curve has been derived from the TG data obtained at different heating rates (b) using Doyle's equation and assuming that $\frac{\mathrm{AE}}{\beta \mathrm{R}} \mathrm{p}\left(\frac{\mathrm{E}}{\mathrm{RT}}\right)$ is a constant for a given function of material decomposed. The function $\mathrm{p}\left(\frac{\mathrm{E}}{\mathrm{RT}}\right)$ was approximated by the equation;:

$$
\log \mathrm{p}\left(\frac{\mathrm{E}}{\mathrm{RT}}\right)=-2.315-0.4567 \quad\left(\frac{\mathrm{E}}{\mathrm{RT}}\right)
$$

so that

$$
-\log \beta=0.4567\left(\frac{\mathrm{E}}{\mathrm{RT}}\right)+\text { constant }
$$

Hence, the activation energy is calculated from the thermogravimetric data obtained at different heating rates. The frequency factor is calculated from the equation:

$$
\log A=\log g(\alpha)-\log \quad\left[\left[\frac{E}{\beta R} p\left(\frac{E}{R T}\right)\right]\right.
$$

Although the calculated activation energy is independent of the reaction model and the frequency factor depends on the determined form of $g(a)$, both $\mathrm{E}$

In the Madhusudanan method ${ }^{(18)}$, the equation used has the form:

$$
-\ln \left[\frac{\mathrm{g}(\alpha)}{\mathrm{T}^{1.921503}}\right]=-\ln \frac{\mathrm{AR}}{\beta \mathrm{E}}+3.7720501-1.921503 \ln \mathrm{E}-\frac{\mathrm{E}}{\mathrm{RT}}
$$

where the symbols have their usual significance. The activation energy $E$ and the frequency factor A are obtained from the slope and intercept of the linear fit of the polt of

$$
-\ln \left[\frac{\mathrm{g}(\alpha)}{\mathrm{T}^{1.921503}}\right] \text { vs. }(1 / \mathrm{T})
$$


In the composite method of analysis of dynamic data ${ }^{(5)}$ the results obtained, not only at different heating rates but also with different a values, are superimposed on one master curve. This has been achieved by rewriting the approximate integral equations due to different workers in a form such that the kinetic function $g(\alpha)$ and the linear heating rate $b$ lie on one side of the equation and $(1 / \mathrm{T})$ on the other side. When use is made of the modified Coats-Redfern equation ${ }^{(14)}$, then in order to do the composite analysis the equation is written in the form:

$$
\ln \left[\frac{\beta \mathrm{g}(\alpha)}{\mathrm{T}^{2}}\right]=\ln \left(\frac{\mathrm{AR}}{\mathrm{E}}\right)-\frac{\mathrm{E}}{\mathrm{RT}}
$$

Hence, the dependence of $\ln \left[\frac{\beta \mathrm{g}(\alpha)}{\mathrm{T}^{2}}\right]$ calculated for different a values at their respective $\mathrm{b}$ values, on $1 / \mathrm{T}$ must give rise to a single master straight line for the correct form of $\mathrm{g}(\mathrm{a})$ and a single activation energy and frequency factor can be readily calculated.

When using Doyle's approximate equation ${ }^{(19)}$ the equation for composite analysis has the form:

$$
\log [g(\alpha) b]=\left[\log \frac{A E}{R}-2315\right]-0.4567\left(\frac{E}{R T}\right)
$$

Again, use may also be made of Madhusndanan. et al. approximate equation $^{(18)}$ rewritten as:

$$
-\ln \left[\frac{\beta \mathrm{g}(\alpha)}{\mathrm{T}^{1.921503}}\right]=-\ln \frac{\mathrm{AR}}{\mathrm{E}}+3.7720501-1.921503 \ln \mathrm{E}-\frac{\mathrm{E}}{\mathrm{RT}}
$$

Again, the dependence of the left side of equations (14) and (15) on (1/T) should give rise to a single master straight line for the correct form of $g(\alpha)$ and hence the activtion energy and the frequency factor can be readily calculated.

In general the use of the different approximate integral equations for the kinetic analysis of nonisothermal decomposition kinetic data according to the composite method of analysis gave rise, within experimental error, to identical values of activation parameters and the correct form of $g(\alpha)$. A computer program has been written to perform the data analysis ${ }^{(5-12)}$

Figure 6 shows the results obtained from non-isothermal measurements for the decomposition reactions, for the samples studied in air at different heating rates of 5,10,15, 20 and $30 \mathrm{deg}$. $\mathrm{min}^{-1}$. 


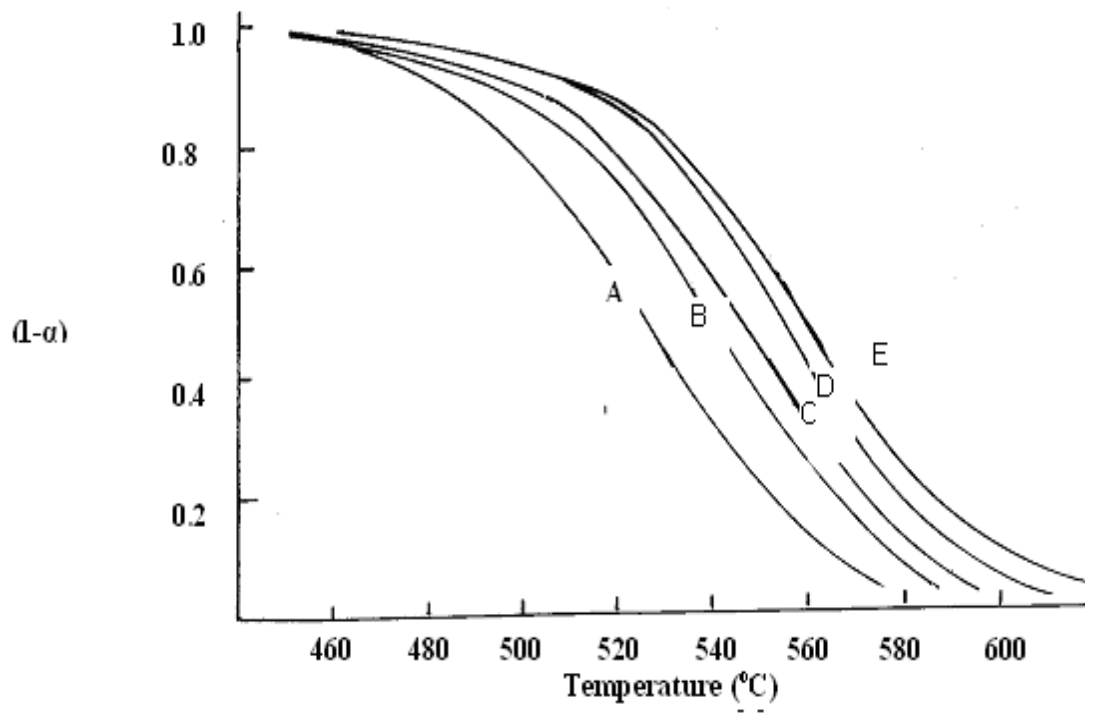

Fig. 6. Dynamic measurements for iron carbonate thermal decomposition with heating rate $\mathrm{A} \mathrm{5,} \mathrm{B} \mathrm{10,} \mathrm{C} \mathrm{15,} \mathrm{D} 20$ and $\mathrm{E} 30^{\circ} \mathrm{C} / \mathrm{min}$.

The activation parameters were calculated and listed in Table 2. The activation parameters obtained under isothermal conditions are similar to those obtained under non - isothermal conditions due to composite method, CoatsRedfern method and Madhusndanan method.

TABLE 2. Activation parameters of the thermal decomposition of iron carbonate calculated according to $D_{3}$ models.

\begin{tabular}{|c|c|c||}
\hline \multirow{2}{*}{ Methods of analysis } & \multicolumn{2}{|c|}{ Decomposition step } \\
\cline { 2 - 3 } & $\begin{array}{c}\mathrm{E}_{\mathrm{a}} \\
\mathrm{kJ} \mathrm{mol}^{-1}\end{array}$ & $\begin{array}{c}\log \mathrm{A} \\
\mathrm{min}^{-1}\end{array}$ \\
\hline Isothermal & $82.3 \pm 1.2$ & $6.85 \pm 0.21$ \\
\hline Composite Method * & $81.4 \pm 1.3$ & $6.90 \pm 0.23$ \\
\hline Coats-Redferm Method & $84.0 \pm 4-0$ & $6.70 \pm 0.5$ \\
\hline Ozawa Method & $112.59 \pm 13.07$ & $9.94 \pm 1.39$ \\
\hline Madhusndanan method & $85.0 \pm 6.0$ & $6.82 \pm 0.7$ \\
\hline
\end{tabular}

* Analysis according to this method were done using integral methods of Coats-Redfern, Madhunsdanan, modified coats-Redfern, ...... etc and the listed values represent average values of the results obtained using the different methods. 
The activation energy for the decomposition of iron carbonate is in agreement with the values of many thermal decomposition reactions. This supports the view that charge transfer is the rate - controlling step in the mechanism of decomposition ${ }^{(22)}$.

\section{References}

1. Galwey, A.K., Thermal reactions of selected solids including reactants that melt during chemical change. J. Thermal Anal. 41, 267 (1994).

2. Galwey, A.K., In MTP International Review of Science, Inorganic Chemistry, Series 2, Solid State Chemistry, Vol. 10, H.J. Emeleus (Ed.), Butterworths, London, P. 147 (1975).

3. Brown, M.E., Introduction to Thermal Analysis, Chapman and Hall Chapter 13 (1988).

4. Chen, D., Gao, X. and Dollimore, D., Computer programs for kinetic analysis of nonisothermal thermogravimetric data. Instrumentation Science \& Technology, 20, 137 (1992).

5. Diefallah, El-H.M., Kinetic analysis of thermal decomposition reactions part VI. thermal decomposition of manganese (II) acetate tetrahydrate. Thermochim. Acta, 202, 1 (1992).

6. Diefallah, El-H.M., Obaid, A.Y., Qusti, A.H., El-Bellihi, A.A. and Abdel Wahab M., Gamma irradiation effects on the kinetics of the non-isothermal decomposition of manganese acetate tetrahydrate. Thermochim. Acta, 274, 172 (1996).

7. Diefallah, El-H.M., Basahel, S.N. and El-Bellihi, A.A., Thermal decomposition of ammonium trioxalatoferrate (III) trihydrate in air. Thermochim. Acta , 290, 123 (1996).

8. Diefallah, El-H.M., Gabal, M.A., El-Bellihi, A.A. and Eissa, N.A., Nonisothermal decomposition of $\mathrm{CdC}_{2} \mathrm{O}_{4}-\mathrm{FeC}_{2} \mathrm{O}_{4}$ mixtures in air. Thermochim. Acta, 376, 43 (2001).

9. Gabal, M.A., El-Bellihi , A.A. and Ata-Allah, S.S., Effect of calcination temperature on Co(II) oxalate dihydrate-iron(II) oxalate dihydrate mixture. DTA-TG, Mössbauer, FT-IR and SEM studies (part II). Materials Chemistry and Physics, 81, 84 (2003).

10. Gabal., M.A., El-Bellihi, A.A. and El-Bahnasawy, H.H., Non-isothermal decomposition of zinc oxalate-iron(II) oxalate mixture. Materials Chemistry and Physics, 81, 174 (2003).

11. Obaid, A., Alyoubi, A.Y., Samarakandy, A.A., Al-Thabaiti, S.A., Al-Juaid, S.S., El-Bellihi, A.A. and Diefallah, El-H. M., Kinetics of thermal decomposition of copper acetate monohydrate. J. Thermal analysis and Calorimetry , 61, 985-994 (2000).

12. Gabal, M.A., Non-isothermal kinetics and characterization studies for the decomposition course of $\mathrm{CuC}_{2} \mathrm{O}_{4}-\mathrm{Cd} \mathrm{C}_{2} \mathrm{O}_{4}$ mixture in air. J. Physics and Chem. Solids, 68, 1610 (2007).

Egypt. J. Chem. 53, No. 6 (2010) 
13. Ozawa, T.A., New method of analyzing thermogravimetric data. Bull. Chem. Soc. Jpn. 38, 1881, (1965) Kinetic analysis of derivative curves in thermal analysis. J. Therm Anal. 2, 301 (1970).

14. Coats, A.W. and Redfern, J.P., Kinetic parameters from thermogravimetric data. Nature, 201, 68 (1964).

15. Xuan, S., Chen, M., Hao, L., Jiang, W., Gong, X. and Chen, Y.Hu, Preparation and characterization of microsized $\mathrm{FeCO}_{3}, \mathrm{Fe}_{3} \mathrm{O}_{4}$ and $\mathrm{Fe}_{2} \mathrm{O}_{3}$ with ellipsoidal morphology. Journal of Magnetism and Magnetic Materials, 320, 164 (2008).

16. Ram, S., Patel, K.R., Sharma, S.K. and Tripathi, R.P., Distribution of iron in siderite in sub-surface sediments of Jaisalmer Basin (India) using Mössbauer spectroscopyuel . Fuel, 77, 1507 (1998).

17. Berry, F.J., The Mössbauer Effect in Supported Microcrystallites. Adv. Inorg. Chem. Radiochem., 21, 255 (1978). Lu, L., Hua. Wansheng, W., Wang., J.G., Stevens and Zhang, Y., Thermal decomposition of unsupported and supported $\operatorname{Sn}_{3}\left[\mathrm{Fe}(\mathrm{CN})_{6}\right]_{4}$ in air. Thermochim. Acta, 195389 (1992).

18. Madhusudanan, P.M., Krishnan, K. and Ninan, K.N. , New approximation for the $\mathrm{p}(x)$ function in the evaluation of non-isothermal kinetic data. Thermochimica Acta, 97, 189 (1986).

19. Doyle, C.D., Series approximations to the equation of thermogravimetric data. Nature, 207, 290 (1965).

20. Zsako, J., Kinetic analysis of thermogravimetric data, III Improvement of Doyle's isothermal method. J. Thermal Anal. 2, 145 (1970).

21. Carroll, B. and Manche, E.P., Kinetic analysis of chemical reactions for nonisothermal procedures. Thermochim. Acta, 3, 449 (1972).

22. Alkac, D. and Atalay, U., Kinetics of thermal decomposition of Hekimhan-Deveci siderite ore samples. Internat. J. Coal Geology, 75, 165 (2008).

(Received 29/9/2010 ; accepted 16/1/2011) 


\section{كينيتكية التكسير الحرارى لكربونات الحديد}

\section{عبد الحميد أحمد أحمد البليهىى}

قسم الكيمياء - كلية العلوم - جمامعة بلبها أحها - بنها - مصر .

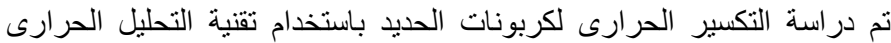

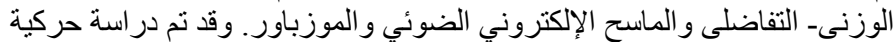

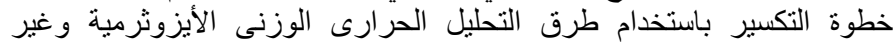

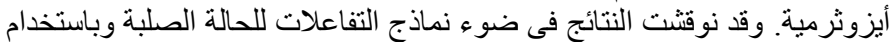
طرق حسابية مختلفة من طريفة التراكم (composite Diefallah) وطرئة وطريقة كوتس - ريدفيرن (Coats-Redfern) وطريقة أوزاوا (Ozawa). تم تحليل

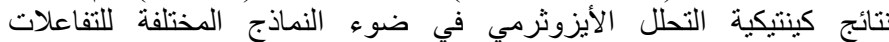

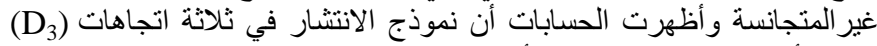



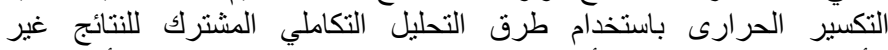

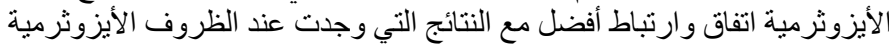

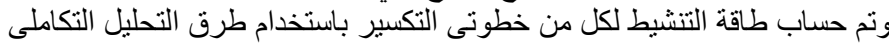

